\title{
TOTAL COST OF OWNERSHIP MODELS ${ }^{\star}$
}

Ron Webber ${ }^{1}$

\begin{abstract}
With the difficult economic challenges currently facing the steel industry, it is essential to perform a complete analysis when determining which rolls to purchase. A properly designed "Total Cost of Ownership" model can result in significant savings. This paper will review the costs associated with rolls in both Hot Strip and Cold Strip Mills. The multitude of factors that must be considered in performing a complete analysis for the roll purchasing process will be discussed. Models for both Hot Strip and Cold Mills will be presented. Examples where traditional analysis can lead to expensive, incorrect decisions will be presented.
\end{abstract}

Keywords: Rolls; Hot Strip Mill; Cold Strip Mill; TCO

1 B. Eng (Met), Global Technical Services Manager, Union Electric Akers, Carnegie, PA, USA 


\section{INTRODUCTION}

Because it is capital intensive, the growth and development of the Steel Industry have been evolutionary in nature. However, Customer demands increase unabated and the Industry has responded in kind. The Customers has requested better dimensional control, stronger and lighter steel and better surface quality. The Steel Mills have responded with new grades and higher quality. This has required better equipment (shifting, bending, CVC, Pair Cross, Lubrication etc.), statistical process control, reliability centered maintenance and advanced computer models.

In order to respond to the demands of the Mill, the Roll Industry has had to improve its processes and grades. New castings techniques have been developed, heat treatment has been improved and new grades have been developed. Rolls have gone from being a consumable to a technology.

Roll performance has improved dramatically, however, this has come at significant cost as the new grades require expensive alloys and extensive heat treatment times. With rolls accounting for typically 5 to $15 \%$ of the total costs of a Hot Strip or Cold Strip Mill, the concept of "Total Cost of Ownership (TCO)" has become very important. There is no single TCO model that can be used by all Mills. So many variables are involved that each Mill must be analyzed for their unique product mix, operating context and local costs.

The main concept to remember is that the roll price is but one of numerous variables affecting what the true cost of the roll is. Focusing on the roll price often results in higher overall costs because other significant variables are not considered.

This paper will look at the history and development of analyzing roll costs and how these became more comprehensive TCO models. Several approaches to TCO will be presented and the advantages and disadvantages of each will be discussed.

\section{TCO DEVELOPMENT}

The concept of Total Cost of Ownership has evolved over the years. This evolution has gone hand in hand with the increasing computerization of Mills and the resultant data available to base the models on. The availability of computers to store massive amounts of data and rapidly manipulate it is a necessity for a modern TCO. In the following paragraphs, the evolution of TCO models will be discussed.

\subsection{Hot Strip Mill}

The oldest TCO models were based on "gut feel". No data was available so roll decisions were based on the subjective perception of whoever had responsibility for buying rolls. Often, a Mill incident would lead to a particular Roll Vendor, fairly or unfairly, being kicked out of the Mill for varying lengths of time.

Not that many years ago, roll records were kept on cardboard cards and there was no connection to the Mill data. Roll performance was based on the time (days, weeks or months) from the when the roll was received until it was scrapped. The biggest of the 
many shortcomings of this method is that a roll could sit in the racks for months without being used and thus have excellent "performance".

For the more ambitious, the tonnage rolled per campaign could be entered on the roll card. The total tons could then be manually added thus resulting in a roll performance based on tonnage. This was a significant improvement, however it could not take into account many important variables. The biggest drawback was probably its inability to easily see how a roll performed through its life. An example would be some of the earliest enhanced ICDP rolls. The carbides would segregate to the outside of the shell resulting in excellent performance initially and then highly reduced performance as the roll reduced in diameter.

The next in progression is performance based on Tons of Product Rolled per $\mathrm{mm}$ of roll stock used $(\mathrm{T} / \mathrm{mm})$. While not really that different from total tonnage, it allows for more accurate benchmarking with other Mills. The total tonnage is highly dependent on the thickness of the shell. This is fine for internal comparisons of different Vendors or roll types, however, it does not permit a comparison with other Mills.

Other variations of $\mathrm{T} / \mathrm{mm}$ are available. These include $\mathrm{mm} / 1000 \mathrm{~T}, \mathrm{~km} / \mathrm{mm}$ and $\mathrm{kg}$ / T. While $\mathrm{mm} / 1000 \mathrm{~T}$ and $\mathrm{kg} / \mathrm{T}$ are basically mathematical manipulations of $\mathrm{T} / \mathrm{mm}$, $\mathrm{km} / \mathrm{mm}$ is a more accurate measurement as it takes into account the thickness of product being rolled. Thinner product puts a greater demand on the rolls and will reduce performance.

As rolls progressed from being a commodity into a technology, cost became more critical. $\mathrm{T} / \mathrm{mm}$ can be easily transformed into a number meaningful to Mill Managers and Company Accountants. As shown below, taking the cost per $\mathrm{mm}$ of shell material and dividing by the tons of product rolled per $\mathrm{mm}$ of shell material yields the cost per ton.

Equation 1: Cost / mm / T/mm $\rightarrow$ Cost / T

This is a very useful number and can be used to compare different roll types (i.e. high chrome iron, HSS, ICDP), rolls from different Vendors and different roll types from different Vendors. In many Mills, this will be sufficient, however, it does not incorporate some potentially critical variables.

Keeping within the context of the Roll Shop and the Mill, other significant variables include roll failures, downtime due to roll failures, the effect of rolls of strip quality and downtime due to unscheduled roll changes. A model that incorporates these variables will be shown later. To perform this analysis takes much more effort and also requires the availability of more data.

The importance of each factor varies dramatically between Mills. For extremely stable Mills, T/mm will capture most of the costs and the extra effort is not required. For less stable Mills that are operating at capacity, downtime costs can be very high. If the Mill is often down due to roll issues, productivity is reduced. This results in less sales and increased Customer dissatisfaction due to delayed shipments. 
The final TCO Model looks at the entire roll process from a broader view. Every aspect is evaluated to determine its cost to the overall process and to identify potential cost savings. While certain factors are universal, there will be local considerations for every Mill.

\subsection{Cold Strip Mill}

While most of the above is also valid for the Cold Strip Mill, there are additional factors that are unique to them. These include the costs of roll surface treatments (EDT, Shotblasting), chrome plating and rehardening.

\section{CURRENT TCO MODELS}

A wide variety of factors can affect the cost of roll usage. For the Hot Strip Mill, these include:

- Roll price

- Roll performance

- Resistance to wear

- Resistance to minor spalling and cracking

- Resistance to catastrophic failure

- Resistance to surface degradation

- Mill downtime due to extra roll changes

- Quality related

- Failure related

- Grinding cost

- Time

- Consumables

- Electricity

- Manpower

- Mill related costs

- Electricity

- Cost of quality

- Mill availability

- Water

- Maintenance scheduling

- Other factors local to specific Mills

To incorporate all these variables into a model would be somewhat burdensome and time consuming. According to the Pareto principle, $20 \%$ of the variables account for $80 \%$ of the problems. Thus, it is up to each Mill to determine the "significant few" variables. In the next section, examples will be given that are valid for many Mills. 
The factors for a Cold Strip Mill are similar with the addition of the following:

- Texturing

- Chroming

\subsection{HOT STRIP MILL TCO - EXAMPLE 1}

This section will describe a TCO based on the Roll Shop / Mill context. The factors included are:

- Roll Performance

- Roll Failures

- Strip Quality

- Unscheduled Downtime

This type of TCO is illustrated in Table I.

Table I - Hot Strip Mill TCO

\begin{tabular}{|l|l|l|l|l|l|l|l|l|l|}
\hline $\begin{array}{l}\text { Roll } \\
\text { Type }\end{array}$ & $\begin{array}{l}\text { Tons } \\
\text { Price }\end{array}$ & $\begin{array}{l}\text { Tons } \\
\text { Rolled }\end{array}$ & \multicolumn{2}{|l|}{ Performance } & \multicolumn{2}{|c|}{ Failures } & Downtime & Quality & Total \\
\hline 1 & 2 & 3 & 4 & 5 & 6 & 7 & 8 & 9 & 10 \\
\hline
\end{tabular}

The first column consists of the different types of rolls that were used. There can be a variety of Suppliers and different types of rolls from individual Supplier included.

The price of the roll is given in Column 2 and the cost per ton is shown in Column 5 (as calculated by Equation 1).

Column 3 is the tons rolled by each roll type during a specific period. This is required to normalize the data.

Column 4 is the roll performance including all incidents.

The next 2 Columns ( 6 and 7 ) deal with roll failures. The residual value of failed rolls is accumulated and divided by the tons rolled to yield a cost per ton.

Column 8 represents the costs due to Mill downtime. This includes both the downtime from roll failures and the downtime due to unscheduled roll changes caused by a variety of conditions (poor surface, marks, poor shape or profile etc.). The time must be multiplied by the Mill operating cost (cost per hour) and divided by the tons rolled by each roll type.

The 9th Column is the quality cost. The quality costs are derived from strip quality problems that are attributable to the rolls. These include surface problems, expression marks and impression marks. 
The calculation of this cost will be very Mill specific. It involves the cost to repair, downgrade or scrap the damaged coil(s).

The last column (10) is the summation of all the costs and represents a Total Cost of Ownership.

While the Normal Operating Cost is easy to determine, some of the others can require sophisticated computer systems.

An example of this is shown in Table II. These were delivery stand rolls (F5 to F7) rolls.

Table 2 - Hot Strip Mill TCO

\begin{tabular}{|l|l|l|l|l|l|l|l|l|l|}
\hline Roll & $\begin{array}{l}\text { Tons } \\
\text { Price }\end{array}$ & $\begin{array}{l}\text { Tons } \\
\text { Rolled }\end{array}$ & \multicolumn{2}{l|}{ Performance } & \multicolumn{2}{l|}{ Failures } & Downtime & Quality & Total \\
\hline & & (MM) & T/mm & $\begin{array}{l}\text { Cost/ } \\
\text { Ton }\end{array}$ & Value & $\begin{array}{l}\text { Cost/ } \\
\text { Ton }\end{array}$ & $\begin{array}{l}\text { Cost/ } \\
\text { Ton }\end{array}$ & $\begin{array}{l}\text { Cost/ } \\
\text { Ton }\end{array}$ & $\begin{array}{l}\text { Cost/ } \\
\text { Ton }\end{array}$ \\
\hline A & 31760 & 2.645 & 2196 & $\$ 0.175$ & 3731 & $\$ 0.001$ & $\$ 0.082$ & $\$ 0.041$ & $\$ 0.300$ \\
\hline B & 31760 & 0.541 & 2429 & $\$ 0.158$ & 0 & $\$ 0.000$ & $\$ 0.026$ & $\$ 0.012$ & $\$ 0.197$ \\
\hline C & 29820 & 0.731 & 2078 & $\$ 0.174$ & 89914 & $\$ 0.123$ & $\$ 0.403$ & $\$ 0.103$ & $\$ 0.802$ \\
\hline D & 33600 & 1.801 & 2889 & $\$ 0.141$ & 130624 & $\$ 0.073$ & $\$ 0.269$ & $\$ 0.098$ & $\$ 0.580$ \\
\hline E & 31680 & 3.279 & 2284 & $\$ 0.168$ & 29561 & $\$ 0.009$ & $\$ 0.085$ & $\$ 0.093$ & $\$ 0.355$ \\
\hline F & 39596 & 2.341 & 2084 & $\$ 0.230$ & 18453 & $\$ 0.008$ & $\$ 0.326$ & $\$ 0.058$ & $\$ 0.622$ \\
\hline G & 34580 & 3.486 & 2137 & $\$ 0.196$ & 7406 & $\$ 0.002$ & $\$ 0.076$ & $\$ 0.031$ & $\$ 0.305$ \\
\hline H & 29419 & 3.102 & 1936 & $\$ 0.184$ & 49508 & $\$ 0.016$ & $\$ 0.068$ & $\$ 0.028$ & $\$ 0.296$ \\
\hline
\end{tabular}

In this example, it can be seen that, based on the Performance Based Operating Costs, Roll Type D (red shaded column) would appear to be the most cost effective. Further analysis showed that these rolls caused many minor quality defects and numerous unscheduled roll changes. Type B (grey shaded column) proved to be the most cost effective roll because of its resistance to failures and quality incidents. In almost all cases, the TCO shows the true cost to be significantly higher than perceived cost. The fact that the TCO resulted in costs that ranged from $\$ 0.197$ to $\$ 0.82$ per ton illustrates the importance of considering all variables.

\subsection{COLD STRIP MILL TCO - EXAMPLE 2}

As previously mentioned, Cold Strip Mills will have additional issues of their own. In this example, a TCO Model developed for comparing Åkers Invicta (HSS) rolls to standard Cr-Mo rolls is shown.

The main additional factors are:

- cost of rehardening

- cost of chrome plating

- cost of grinding

- cost of chock handling 
While the initial price of Invicta rolls is higher, longer campaigns, fewer chock changes, less grinding, no rehardening and no chrome plating results in a significant reduction in overall cost.

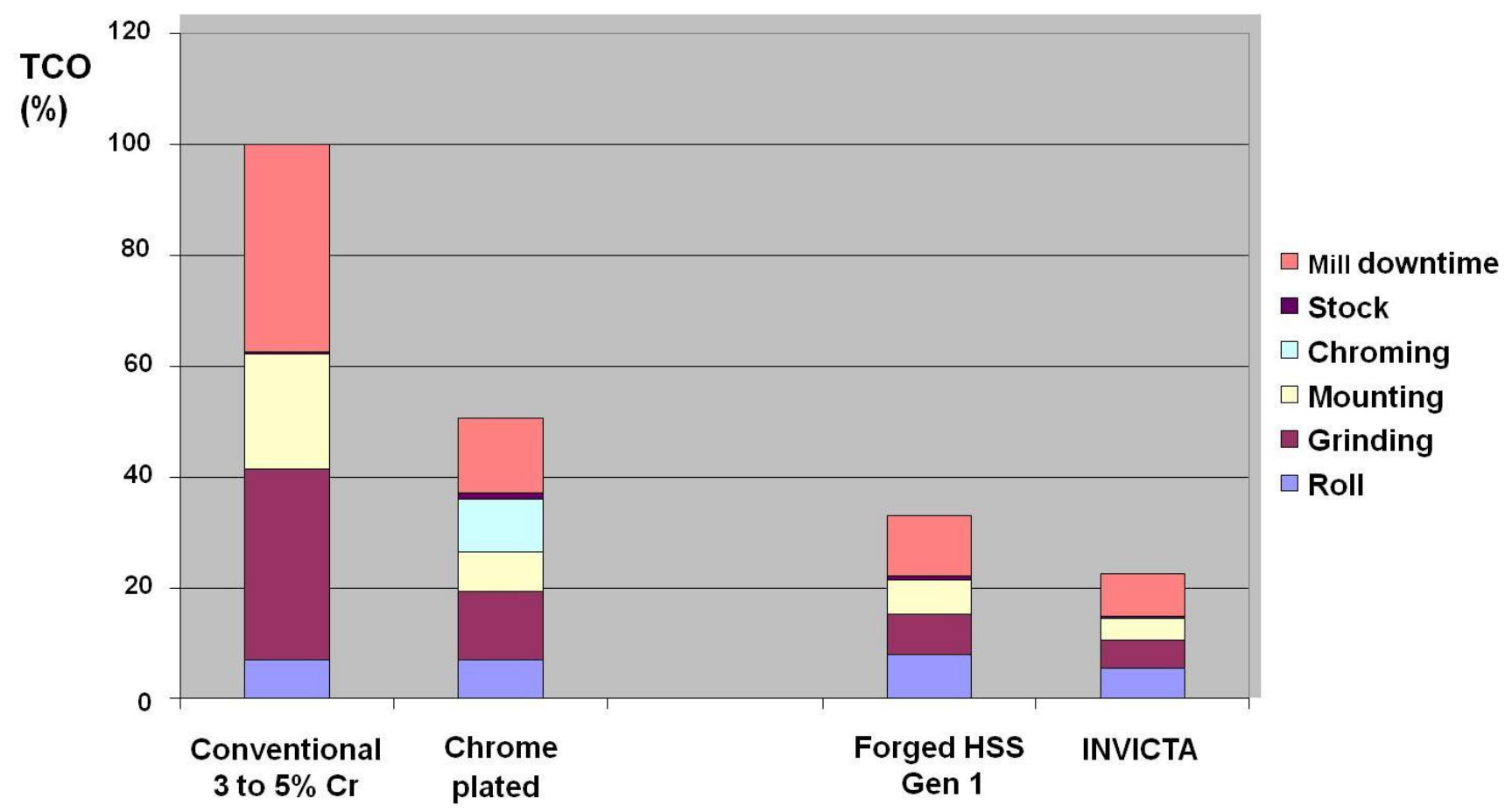

Figure $1^{1,2}$ - Cold Strip Mill TCO - Invicta

\subsection{ALL MILLS TCO - EXAMPLE 3}

The TCO can be looked at from a broader view. While it is probably not necessary to perform this type of analysis on a regular basis, it shows a truer TCO that can be used to identify additional high cost factors. It looks at all the factors that come into play during the life cycle of a roll. This must be done for each type of roll (HSS, High Chrome Iron, ICDP, 5\% Cr-Mo etc.) as different issues will arise for each. 


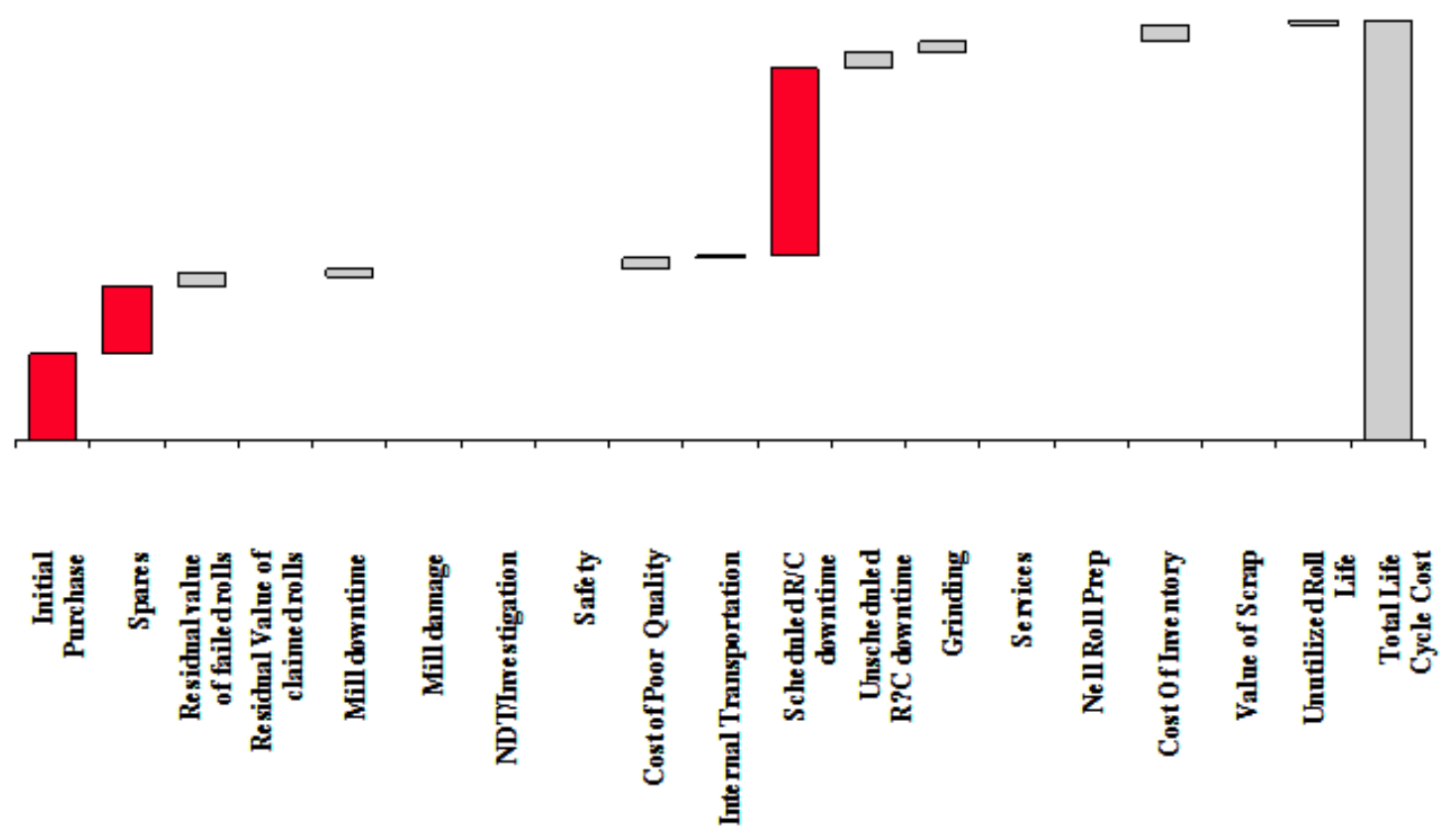

Figure 2 - Hot Strip Mill TCO

In this example, a cross functional team performed a brainstorming session and came up with as many variables as possible. Further analysis showed some to be irrelevant. The major factors were the cost of spares and scheduled downtime for roll changes (shown in red). This resulted in the initiation of 2 Projects - Inventory and Roll Change Time. A full analysis of Inventory Level showed that there was room for limited reduction and resulted in an improved system to monitor inventory on a monthly basis.

The Roll Change Project resulted in a significant reduction in roll change time by improving the equipment and systems were put in place to ensure that the gains were sustained.

Other Mills will have their own unique circumstances. Many Mills do not have enough grinding capacity and must out-source. This can be a significant cost, especially if the Contractor does not have NDT equipment and must remove a standard stock to ensure safety.

In most cases, the original cost of the roll is a minor component of the Total Life Cycle Cost.

\section{OTHER CONSIDERATIONS}

A complete TCO can also consider other factors that are difficult or sometimes impossible to put a monetary value on. These include:

- Claims handling and resolution

- Technical support for rolls

- Technical support for other Mill issues

- On time delivery 
Often, these can be major factors in the overall evaluation. The Roll Supplier can be a valuable partner in a Mill's quest for continuous improvement.

\section{CONCLUSIONS}

A Total Cost of Ownership Model can take many forms. It is critical to evaluate which factors are important to each Mill and to incorporate them into the model. Once a Model is developed, it is a powerful tool to properly evaluate the true costs of Mill rolls and make decisions on which rolls are best for each application.

\section{REFERENCES}

1 Gaspard, C.; Vergne, C.; Batazzi, D. Implementation of HSS Grade in Cold Rolling Applications. Roll 4 2007, Birmingham, UK, March 2007.

2 Gaspard, C.; Vergne, C.; Adams, T. Performance Overview of Forged HSS Rolls for Cold Rolling in Steel Industry. Roll 5 2015, Birmingham, UK, April 2015. 